\title{
A Survey on the Impact of COVID 19 on Undergraduate and Postgraduate Medical Education in Qatar
}

M Thomas ( $\nabla$ mmts1983@gmail.com )

Hamad general Hospital

\section{S Suleiman}

Hamad General Hospital

M Allen

Hamad General Hospital

M Hameed

Hamad general Hospital

A Ghaffar

Hamad General Hospital

MM Emara

Hamad General Hospital

H Fatima

Hamad General Hospital

$S$ George

Hamad General Hospital

R Singh

Hamad General Hospital

H Ghazouaini

Hamad General Hospital

\section{AL Alkhal}

Hamad General Hospital

\section{Research Article}

Keywords: COVID-19, Medical Education, Survey

Posted Date: October 28th, 2021

DOl: https://doi.org/10.21203/rs.3.rs-940106/v1 
License: (c) (i) This work is licensed under a Creative Commons Attribution 4.0 International License. Read Full License 


\section{Abstract}

\section{Background}

COVID-19 pandemic has affected all dimensions of day to day life across the world and medical education was no exception. In Qatar, two institutions provide undergraduate medical education; Qatar University - College of medicine and Weill Cornell Medical College, Qatar and post graduate medical education is provided by tertiary care public hospitals under Hamad Medical Corporation (HMC) through Accreditation Council for Graduate Medical Education -International (ACGME-I) accredited residency and fellowship programs. With this study we aimed to understand the impact of nationwide restrictions on medical education in Qatar.

\section{Methods}

We conducted a cross sectional study utilising an online questionnaire between April and October 2020. Two questionnaires for the faculty and trainees each were designed to address the objectives. The questionnaires addressed barriers to delivery of medical education and perceptions on the models of education used.

Results

Majority of trainees (58.5\%) responded that the pandemic has adversely affected medical education at both the undergraduate and postgraduate levels. Trainees (58.5\%) and faculty $(35.7 \%)$ reported an increased reliance on e-learning. Trainees preferred face to face education (33.5\%) while the faculty (37.1\%) preferred a combination of different models of education delivery. Although $52.5 \%$ of the faculty had no previous experience of delivering education using e-learning modalities, but $58.9 \%$ felt confident in using e-learning software.

\section{Conclusions}

Faculty and trainees agree that the COVID-19 pandemic has had a significant impact on the provision of medical education and training in Qatar, with an increased dependence on e-learning. As trainee's prefer face-to-face models of education, we may have to consider restructuring of medical curricula in order to ensure that optimum learning is achieved via e-learning, while at the same time enhancing our use, knowledge and understanding of the e-learning methods as they may be an essential way of delivering education in the future.

\section{Introduction}

The year 2020 will be synonymous with the acronym COVID 19. The SARS-CoV-2 virus spread rapidly across continents, resulting in the COVID 19 pandemic ${ }^{1}$. As the virus demonstrated quick and efficient human-to-human transmission even from those who were asymptomatic, WHO recommended social distancing, defined as maintaining at least 6 feet of distance between people and avoiding large crowds 
and public places ${ }^{2,3}$. This important measure has led to businesses, economies and institutions adapting to new models of working and sustainability; medical education was no exception.

Nationwide lockdown restrictions were implemented in Qatar on March 9, 2020 resulting in the closure of schools and universities ${ }^{4}$. In the state of Qatar, two institutions are providing undergraduate medical education, Qatar University - College of medicine (QU CMED) and Weill Cornell Medical College, Qatar (WCMQ). Post Graduate Medical Education is provided by the teaching hospitals under the government run Hamad Medical Corporation (HMC) through residency and fellowship training programs (ACGME-I accredited). HMC implemented stringent infection control measures including restricted entry to visitors, trainees and outpatients, with the introduction of telemedicine for many outpatient encounters. Clinical and non-clinical staff were mobilised to three new COVID 19 designated hospitals to deal with the unprecedented burden of the pandemic ${ }^{5}$. For much of this extraordinary effort HMC stopped or restricted most routine educational activities. As undergraduate and postgraduate medical education in Qatar relies predominantly on the traditional face-to-face methods, these restrictions mandated a shift in the models of learning to e-learning or online learning 6,7 .

To understand the impact of the implemented nationwide restrictions and deployment of the healthcare workforce to COVID hospitals on the continuity of medical education, we conducted a cross-sectional study with an online survey. The study aimed to explore the factors hindering education and the resourceful models and educational tools used to minimise disruption of medical education for trainees. We also looked at the perceptions of the trainees and faculty, related to these new models of delivery of medical education. The survey was administered to two cohorts, one being the undergraduate medical trainees and faculty at QU CMED, and the second being the postgraduate trainees and faculty of ACGME-I accredited programs at HMC.

\section{Materials And Methods}

This was a cross sectional study conducted utilising an online survey questionnaire between April and October 2020.

\section{Questionnaire Design and Distribution}

Questionnaires were designed to gather precise information and insight into the effects of the current ongoing global COVID-19 pandemic on medical education. Two sets of questions were framed for the target participants who were categorized into two pre-defined groups, one consisting of trainees and the other consisting of faculty. The initial trainee and faculty questionnaires consisted of 24 questions, which were reduced to 18 questions following an expert panel discussion. This was done by combining some of the questions and removing others of less relevance. The format consisted of binary, multiple-choice and Likert scale type questions. However, for some questions a descriptive answer could be provided by choosing the option "Other: Please specify". 
Both trainee and faculty questionnaires were submitted for content and construct validation to five experts in the field of medical education who reviewed for content validity ${ }^{8}$. Content validity indices were computed based on the expert's rating of the item's relevance towards the objectives of the study. Each item was graded as, not relevant, somewhat relevant, quite relevant or highly relevant. The calculated Item-content validity index (I-CVI) across all items was 0.95 for both faculty and trainee surveys. The Scale-level content validity index based on the universal agreement method (S-CVI/UA) for faculty and trainee surveys across all items was 0.8 and 0.7 respectively. Further changes were made to the questionnaire based on the expert recommendations to reach I-CVI of 1.0 and S-CVI/UA $\geq 0.8$. The final version consisted of 13 questions for the faculty and 11 questions for the trainees. The final survey explored three themes: 1. General demographics 2. Status of medical training, and 3. Models of education: Perceptions and preferences with focus on e-learning. The responses were collected and categorised after thematic analysis.

To assess test - retest variability, the questionnaire was piloted among fifteen participants for each survey. This was done twice fifteen days apart to evaluate if the answers given, matched their earlier responses. The Cronbach's alpha for all items was 0.98 for faculty survey and 0.981 for trainee survey indicating a good level of internal consistency. The results of the pilot validation were not included in the final analysis.

The survey was created using Qualtrix, an online survey software. It was distributed via email, and social media. The survey was accessible via an anonymous link for a 2-week period from September 10,2020. This was followed by 3 reminders to the participant's email. At the end of the 2-week period the survey was automatically disabled.

\section{Participants}

The participants were either medical trainees/students or teaching faculty who were distributes as follows:

A) Medical trainees falling under any one of the following categories

1 - Qatar University College of Medicine medical students

2-ACGME-I accredited Residency programs under Medical Education, HMC

3- ACGME-I accredited Fellowship programs under Medical Education, HMC

B. Teaching faculty under the following

1- Qatar University College of Medicine

2- Faculty in ACGME-I accredited Residency programs under Medical Education, HMC

3- Faculty in ACGME-I accredited Fellowship programs under Medical Education, HMC 


\section{Ethical considerations}

Participation in the research was voluntary. All data collected was anonymous. Consent and single submission of the survey by each participant was through 2 initial mandatory questions. The study was ethically approved by the Institutional Review Boards of Hamad Medical Corporation (\#MRC-01-20-1068) and Qatar University.

\section{Data Analysis}

Data recorded in Qualtrix survey software was exported to Microsoft Excel (Excel Version 2008).

Descriptive statistics were used to summarize and determine the sample characteristics and distribution of various considered parameters. Median and range were used to describe the continuous variables with normal distribution. Frequencies and proportions were used for categorical variables. Differences between groups were evaluated with t-test or Wilcoxon signed-rank test for nonparametric continuous variables, and the $\mathrm{Chi}^{2}$ test or Fisher exact test for categorical variables alone. Spearman and Pearson correlation coefficient were used to evaluate correlation between the variables when appropriate. P-value $<0.05$ was considered statistically significant. STATA software version 12.0 (Stata corp, College Station, TX, USA) was used for exploratory data analysis and descriptive statistics and Sigma Plot software was used to create graphs. At the time of statistical analysis, missing data were handled primarily by complete case analysis. As a secondary analysis, missing data were imputed using multiple imputation method.

\section{Results}

\section{Trainee Survey.}

\section{Demographics}

The trainee survey was distributed to 324 medical students and 796 post graduate trainees. The response rate was $156(48 \%)$ from medical students and 193 (24\%) from post graduate trainees. (Table 1) 
Table 1

Demographics of Faculty and Trainee for

Survey

\begin{tabular}{|ll|}
\hline Institution & N (\%) \\
\hline Faculty Survey & \\
\hline Hamad Medical Corporation & $191(91.4)$ \\
\hline Qatar University (Medicine) & $18(8.6)$ \\
\hline Trainee Survey & \\
\hline Medical student & $156(44.8)$ \\
\hline Post graduate trainees (total) & $192(55.1)$ \\
\hline Residency & $143(41.1)$ \\
\hline Fellowship & $49(14.0)$ \\
\hline Surgical speciality & $48(25.0)$ \\
\hline Medical speciality & $118(62.0)$ \\
\hline Other specialty & $26(13.5)$ \\
\hline
\end{tabular}

\section{Barriers to education and adaptation to COVID 19}

A majority of the trainees (58.5\%) responded that the pandemic has adversely affected their training, with no significant difference between medical students and post graduate trainees of surgical or medical specialities $(p=0.208)$. Their specific reasons are categorized in Table 2.

Of the trainees, $49 \%$ reported a suspension of face-to-face educational activities due to the pandemic, while $7.4 \%$ reported not being able to attend due to serving at the 'front line'. Only $12.6 \%$ trainees reported a complete cessation of all forms of educational activities. There was a significant drop in the frequency of all educational activities depicted in Fig. 1, at both undergraduate and post graduate levels during the survey period $(p<0.001)$. 
Table 2

Impact of the current COVID-19 pandemic on trainees

\section{Theme}

Scope of practice

Case Load profile

Education (Theoretical)

Education (Practical)

Majority of postgraduate trainees deployed voted to COVID facilities

Cancellation of elective surgeries.

Lack of diversity of clinical cases

Cancellation of face-to-face activities

Difficulty to engage with online activities

Cancellation of bedside and clinical skills teaching sessions

Delayed or cancelled clinical or clerkship rotations

Impact on Learning Spaces

Closure of libraries and study lounges

Impact on communication and interaction

Workload

Travel and infection Control

Restrictions
Less interaction with patients, colleagues, and supervisors

Increased pandemic related workload

Inability to return to Qatar in view of lockdown and flight restrictions

Presence of Comorbidity that is a risk factor for COVID

\section{Quotations:}

"Decreased my interactions with patients and other health care professionals so I feel my clinical skills were not as sharp as before."

"I can't visit campus all lessons are online even the practical ones which makes it hard especially for clinical practice sessions and lab sessions."

"Less exposure to cases either Emergency or Elective as it was cancelled due to COVID 19, no face to face educational activities."

Thematic analysis of trainees' comments on impact of the current COVID-19 pandemic on their training

Qualitative analysis of the trainees' comments on the impact of the COVID-19 pandemic on their training revealed many themes summarized in Table 2. The change in the scope of service with postgraduate trainees being deployed to COVID facilities resulted in many missing planned rotations. At the peak of the pandemic medical students were not allowed to enter hospitals resulting in shortening or cancellation of clerkship rotations. One dramatic effect was the fast and significant shift in general of undergraduate educational activities to online. However, almost all postgraduate educational programs stopped completely for at least the initial few months of the pandemic, with a detrimental effect on practical bedside and procedural skills teaching. Because of the fear of COVID infection, trainees also had less 
exposure to patients and less interaction with colleagues and supervisors, thereby decreasing experiential learning.

\section{Models of education and perceptions}

Since the start of the pandemic educational activities were delivered predominantly online with $57 \%$ of the trainees receiving e-learning. Of these, the majority received live online lectures $65.6 \%$, followed by broadcast of recorded lectures $20.1 \%$ and sharing of learning material links $23.5 \%$. Given the experience of online teaching during COVID-19 pandemic, only $7.1 \%$ preferred e-learning alone, whereas $33.5 \%$ trainees still prefer face to face education, followed by $26.1 \%$ preferring a combination of face to face learning combined with either synchronous or asynchronous e-learning or self-directed learning strategies. The reasons of trainee's preference for face to face learning are summarized in S1 Table, where interaction with mentors, peers and activity engagement stood out as the most important reasons.

These results were confirmed by the trainees ranking their perceptions of e-learning on a Likert scale ranging from Strongly agree to Strongly disagree $(n=186)$. E-learning was also perceived to be less effective than face to face learning by $53.8 \%$ trainees, whereas $33.3 \%$ agreed to strongly agreed that elearning is as effective as traditional methods of delivery of education. Moreover, $56.9 \%$ and $32.2 \%$ trainees showed a level of agreement ranging from agree to strongly agree in stating that e-learning enhances their knowledge and improves their communication skills, respectively. However, $58.6 \%$ agreed that e-learning is effective in integrating different multimedia forms of delivering quality education.

\section{Faculty survey}

The faculty survey was distributed to 40 members of QU faculty and $600 \mathrm{HMC}$ faculty staff with a response rate of $45 \%$ and $31.8 \%$ respectively. (Table 1 )

\section{Demographics}

As HMC postgraduate faculty may also teach at QU there is an overlap in faculty affiliations, however the majority of respondents were faculty at HMC. (Table 1) The postgraduate trainee target group of learners taught by the faculty included: Residents 139 (68.8\%), Fellows 122 (60.4\%); Medical students 79(39.1) and other faculty 99 (49\%).

\section{Challenges in providing medical education during COVID 19.}

Similar to trainee's results, faculty members reported a decreased frequency of educational activities with complete cessation of sessions during the pandemic as reported by $22.8 \%$ of the faculty members. Majority of the faculty, $82.7 \%$, agreed to strongly agreed that there were barriers to deliver medical education during the pandemic due to: (1) implementation of social distancing measures (54.9\%), (2) unavailability of trainees at the bedside or in a classroom (50.5\%), (3) reprioritization of clinical tasks (50\%), (4) infection control policies (47\%), and (5) lack of time during the pandemic (30.7\%). However, the 
majority, $67 \%$, agreed that service delivery and medical education both are equally important during the pandemic. Importantly, the most common challenges faced by the faculty during the pandemic were mental stress $(66.8 \%)$, management of work life balance (56.9\%), and staying up to date with the continuing professional development requirements (53\%). (Fig. 2)

\section{Models of education and perceptions}

Prior to the pandemic, the most common model of delivery of education was face-to-face activities including didactic lectures, workshops, seminars, journal clubs and bedside teaching while e-learning was utilised in $16.3 \%$ activities only. However, since the start of the pandemic there was an increased reliance on e-learning with $19.3 \%$ synchronous lectures, $4 \%$ asynchronous activities and $12.4 \%$ electronic provision of learning materials. Didactic and bedside teaching reduced to $9.9 \%$. Self-directed learning was encouraged by $17.3 \%$ of the faculty. The most effective teaching modality from the faculty's view was perceived to be a combination of face to face, self-directed and e - learning $37.1 \%$, whereas $34.2 \%$ felt that face to face learning alone is the most effective form of educational delivery. The detailed reasons are listed in S2 Table.

Although $52.5 \%$ of the faculty had no previous experience of delivering education using e-learning modalities, 58.9\% however, felt confident in using e-learning software. (Fig. 3) One of the benefits of elearning reported by the faculty was their ability to provide course material to both learners and their colleagues (72.8\%). Other reported benefits included real time presentations to the students $69.3 \%$, developing learner's understanding of the subject $65.4 \%$, and the ability to create innovative teaching materials $64.9 \%$. E-learning was also felt to be an effective tool to communicate with learners outside the classroom (65.4\%), and a way of providing one-to-one attention for learners (46\%). Ease of testing learners (49\%), tracking their progress (49.5\%) and managing individual targets for learners (48\%) also showed a high degree of agreement. Some faculty members also highlighted their scepticism or concerns in using e-learning methods which are elaborated in S3 Table.

\section{Discussion}

Our survey highlights that the COVID 19 pandemic has had a significant impact on the continuity of medical education at both undergraduate and postgraduate institutions. Not only the frequency of educational activities but their mode of delivery was affected. This is not surprising considering the nationwide restrictions imposed to reduce the burden of the disease.

Although initially educational activities were temporarily halted completely, the majority of the postgraduate and undergraduate educational institutions adapted very quickly and restarted through virtual or e-learning platforms after a short break. This adaptation to provide continuing education via elearning has been an international strategy. In the UK, medical colleges also provided virtual learning ${ }^{9}$, however, a survey of final year UK medical students, reported $77.3 \%$ medical elective placements being cancelled with only $1.6 \%$ being replaced by formative online modules ${ }^{10}$. Similarly, at a postgraduate level residency training programs in Canada ${ }^{11}$, ACGME accredited residency programs in the US ${ }^{12}$ and 
speciality residency programs like neurology ${ }^{13}$ started relying on e-learning tools for continuing didactic lectures and providing training in skills and procedures. Our study has also shown the same trend with QU CMED and HMC moving from a predominantly face-to-face delivery of education to online learning albeit after a short break. This is understandable as organisations needed some time to develop and establish remote learning capabilities and protocols.

This paradigm shift in the mode of delivery of medical education through a virtual environment was very swift and hence the long-term realization of its efficacy is crucial to medical education. An objective assessment of this however, could not be done at the time of this survey and hence the perceptions of effectiveness ascertained through our survey showed a dichotomous view for trainees and faculty. Both undergraduate and postgraduate medical trainees in our survey considered face-to-face education to be the most effective mode of delivery. Similarly, in a survey of dental students from Indonesia, only $44.2 \%$ preferred distance learning to classroom learning ${ }^{14}$. Medical students in the UK also shared similar views of not finding e-learning enjoyable or engaging and a majority found it less effective than face-to-face education ${ }^{15}$. In a survey of Libyan medical students only $38.2 \%$ agreed that e-learning can replace traditional models of teaching, although $54 \%$ agreed that interactive discussions were possible via e learning ${ }^{16}$. Trainees in our survey also agreed that e-learning encourages communication and interaction while integrating different forms of media. The anonymity that virtual environments provide, may encourage trainees to interact and engage during synchronous e-learning activities, unlike face-to-face learning, where the environment may be intimidating. In our survey medical students gave a more favourable response to the effectiveness of online learning in enhancing knowledge compared to postgraduate trainees. This can be explained by different aims of their curriculums whereby postgraduate trainees have predominantly practice-based learning that combines theory, procedures, and clinical skills for a comprehensive training while our early years undergraduate curriculum is mainly focused on acquisition of content knowledge. Numerous challenges were also faced by the medical fraternity affecting postgraduate medical education during the pandemic. A shortage of personal protective equipment and lack of sufficient testing in some nations contributed to trainees reluctance to actively participate in training. Another factor contributing to lesser clinical exposure was the significant drop in the number of patients seeking medical care for conditions other than COVID-19. Telemedicine was adopted as a novel care delivery method across many nations including Qatar for non-urgent medical ailments, which further limited the direct contact and assessment of trainees. Trainees were therefore being taught mostly through e-learning platforms rather than in a clinical environment. This transformation of delivery of skills and training during the COVID-19 pandemic may well play a role in medical training and practice of the future, especially for this generation of trainees. A survey of US medical students has shown that two out of five students feel that changes in medical education during the COVID-19 pandemic will impact their ability to practice medicine ${ }^{17}$. Hence, it becomes key to segregate objectives that can be delivered well online and deliver them during the restrictions, while postponing the objectives that require physical presence such as clinical examinations and patient contact in the hope of the pandemic easing. Curricula adaptations must ensure that the standard of 
medical education is not lowered while ensuring that the frontline workforce is being trained to develop the skills and competencies required to serve during the pandemic and well beyond.

Although trainees in our survey did not lean towards a strong agreement on the effectiveness of virtual learning, faculty on the other hand found it to be an effective tool not only in providing quality teaching sessions but also for improved communication with learners and colleagues, sharing learning materials and creating innovative teaching materials to enhance the learner's understanding. The majority of the faculty had no experience with elearning previously however were confident about providing education in a virtual environment. This confidence in virtual teaching likely stems from our exposure to personalized learning experiences through online modules and accredited courses on various online platforms ${ }^{18}$. Similar findings were noted in a survey conducted in India with $56 \%$ faculty having good knowledge of elearning with a high degree of acceptability of the benefits of e-learning ${ }^{19}$. These perceptions also reflect the efficiency and user-friendly configurations of commonly used virtual platforms in our institutions such as Zoom, WebEx Microsoft Teams and Google classroom. As noted by Zaiyed et al, with the number of e-learning platforms available it is worthwhile to have an objective comparison to evaluate the most effective platform, as online learning might become an integral part of future medical education ${ }^{20}$. Until such objective evaluations are available, students must be motivated to integrate self -directed learning with easily accessible mentor support in this virtual learning environment to gain understanding and confidence ${ }^{21}$.

The limitations of this study include the delivery of the survey to the respondents (which depended on the integrity of servers as well as technical capability). Although the survey was validated with excellent reliability indices, all survey-based studies have inherent limitations due to their subjective interpretation and perceptions. Response rates of post graduate trainees and faculty were low, which we attribute to the increasing workload secondary to the pandemic.

In conclusion, the COVID-19 pandemic has had a significant impact on provision of medical training in Qatar as agreed by both the trainees and faculty, with an increased reliance on e-learning modalities. Trainee preference for face-to-face models of education in this time of a switch towards virtual learning mandates a redesign of the medical curriculum in terms of delivery and effectiveness in creating a competent medical work force for the future. However, the increased focus and use of e-learning will also lead to us learning more about the advantages or disadvantages of these activities, which will enable us to incorporate and adapt them better (or not use them at all) in the future as delivery modes for medical education. In an era of robotic and remote surgeries one cannot help but wonder how much tools like virtual and augmented reality and online simulation hold for the future of medical education and training. Our sudden but forced switch to electronic forms of learning in the face of the pandemic may therefore turn out to be a blessing in disguise.

\section{Abbreviations}


WCMQ (Weill Cornell Medical College, Qatar), ACGME-I (Accreditation Council for Graduate Medical Education - International), QU CMED (Qatar University - College of medicine), HMC (Hamad Medical Corporation)

\section{Declarations}

Ethics approval and consent to participate -

All methods were carried out in accordance with relevant guidelines and regulations as laid down by MRC (- Medical Research Center) All experimental protocols were approved by MRC at HMC (Hamad Medical Corporation). Informed consent was obtained from all subjects involved in the study.

Consent for publication - Consent taken from all co-authors to publish

Availability of data and material -With primary author upon request can be shared.

Competing interests - Not Applicable

Funding - Medical Research Center (MRC)

Authors' contributions :

MT - Conceptualization ,Designing , Survey Validation , Data collection , Data analysis , Manuscript writing, Manuscript review

HF- Conceptualization, Designing, Survey Validation, Manuscript writing , Manuscript review, Research protocol write-up

AA - Manuscript writing , Manuscript review

HG-Survey Validation , Data collection, Manuscript review

RS - Data analysis, Manuscript writing, Manuscript review

SG-Survey Validation , Data collection, Manuscript review

ME-Survey Validation, Data collection, Manuscript review

AG- Conceptualization, Designing, Survey Validation, Data collection, Manuscript review 
MH - Data analysis, Manuscript writing, Manuscript review

MA -Conceptualization, Designing, Survey Validation, Manuscript review

SS- Conceptualization ,Designing, Survey Validation , Data collection, Data analysis , Manuscript writing , Manuscript review

All authors have read and approved the manuscript

Acknowledgements - none

\section{References}

1. Murphy B. COVID-19: how the virus is impacting medical schools. Am Med Assoc. 2020. https://www.ama-assn.org/delivering-care/public-health/covid-19-how-virus-impacting-medicalschools Updated MAR 18, 2020. Accessed June 3, 2021

2. Desai AN, Patel P. Stopping the spread of COVID-19. Jama. 2020;323(15):1516. doi: 10.1001/jama.2020.4269

3. Kronbichler A, Kresse D, Yoon S, Lee KH, Effenberger M, Shin JI. Asymptomatic patients as a source of COVID-19 infections: A systematic review and meta-analysis. Int J Infect Dis 2020;98:180-186. doi: 10.1016/j.jijid.2020.06.052

4. Qatar announces closure of schools, universities over coronavirus. Al Jazeera. https://www.aljazeera.com/news/2020/3/9/qatar-announces-closure-of-schools-universities-overcoronavirus March 9, 2020.

5. COVID Facilities and Services. https://www.hamad.qa/EN/COVID19/COVID-Facilities-andServices/Pages/default.aspx. Accessed May 12, 2021

6. QU continues educational system through virtual learning. The Peninsula. https://thepeninsulaqatar.com/article/13/03/2020/QU-continues-educational-system-throughvirtual-learning. March 13, 2020

7. Qatar ministry introduces new blended learning plan for schools. Online Qatar. https://www.onlineqatar.com/news/latest-news/2020/qatar-ministry-introduces-new-blendedlearning-plan-for-schools. August 24, 2020

8. Singh R, Agarwal TM, Al-Thani H, Al Maslamani Y, El-Menyar A. Validation of a survey questionnaire on organ donation: An Arabic world scenario. Journal of Transplantation, vol. 2018, Article ID 9309486, 10 pages, 2018. https://doi.org/10.1155/2018/9309486

9. Gishen F, Bennett S, Gill D. BMJ Opinion. Covid-19-the impact on our medical students will be farreaching.https://blogs.bmj.com/bmj/2020/04/03/covid-19-the-impact-on-our-medical-students-willbe-far-reaching/. Updated April 3, 2020. Accessed May 10, 2020 
10. Choi B, Jegatheeswaran L, Minocha A, Alhilani M, Nakhoul M, Mutengesa E. The impact of the COVID-19 pandemic on final year medical students in the United Kingdom: a national survey. BMC medical education. 2020 D;20(1):1-1. https://doi.org/10.1186/s12909-020-02117-1

11. Virtual Teaching Resources. Royal College of Physicians and Surgeons Canada. https://www.royalcollege.ca/rcsite/documents/about/covid-19-virtual-teaching-resources-e. Accessed April 2021

12. Reed DS, Hill MD, Justin GA, Giles GB, Santamaria JA, Hobbs SD, Davies BW, Legault GL. Finding Focus in Crisis: Resident-Driven Graduate Medical Education at a Military Training Facility during the COVID-19 Pandemic. Mil Med 2020;185 (11-12):469-71. https://doi.org/10.1093/milmed/usaa193

13. Yadala S, Nalleballe K, Sharma R, Lotia M, Kapoor N, Veerapaneni KD, Kovvuru S, Onteddu S. Resident Education During COVID-19 Pandemic: Effectiveness of Virtual Electroencephalogram Learning. Cureus. 2020;12(10). doi:10.7759/cureus.11094

14. Amir LR, Tanti I, Maharani DA, Wimardhani YS, Julia V, Sulijaya B, Puspitawati R. Student perspective of classroom and distance learning during COVID-19 pandemic in the undergraduate dental study program Universitas Indonesia. BMC medical education. 2020;20(1):1-8. https://doi.org/10.1186/s12909-020-02312-0

15. Dost S, Hossain A, Shehab M, Abdelwahed A, Al-Nusair L. Perceptions of medical students towards online teaching during the COVID-19 pandemic: a national cross-sectional survey of $2721 \mathrm{UK}$ medical students. BMJ open. 2020 1;10(11): e042378. doi: 10.1136/bmjopen-2020-042378

16. Alsoufi A, Alsuyihili A, Msherghi A, Elhadi A, Atiyah H, Ashini A, Ashwieb A, Ghula M, Ben Hasan H, Abudabuos S, Alameen $\mathrm{H}$. Impact of the COVID-19 pandemic on medical education: Medical students' knowledge, attitudes, and practices regarding electronic learning. PloS one. 2020 25;15(11):e0242905. doi:10.1371/journal.pone.0242905

17. Megan Brooks.COVID -19 Taking a Toll on Med students, Survey Shows. Medscape. https://www.medscape.com/viewarticle/939798 Updated Oct 26, 2020. Accessed Nov 10, 2020

18. O'Doherty D, Dromey M, Lougheed J, Hannigan A, Last J, McGrath D. Barriers and solutions to online learning in medical education-an integrative review. BMC Med Educ. $2018 ; 18(1): 1-1$. https://doi.org/10.1186/s12909-018-1240-0

19. Joshi KP, Jamadar D, Dixit R. Perception of faculty toward online teaching and learning in the undergraduate medical students during coronavirus disease-19 pandemic. Int J Med Sci Public Health. 2020; 9(8): 484-487. doi:10.5455/ijmsph.2020.09149202008092020

20. Saiyad S, Virk A, Mahajan R, Singh T. Online Teaching in Medical Training: Establishing Good Online Teaching Practices from Cumulative Experience. Int J Appl Basic Med Res. 2020;10(3):149-155. doi: 10.4103/ijabmr.IJABMR_358_20. PMID: 33088735; PMCID: PMC7534709

21. Sani I, Hamza Y, Chedid Y, Amalendran J, Hamza N. Understanding the consequence of COVID-19 on undergraduate medical education: Medical students' perspective. Ann Med Surg (Lond). 2020 5;58:117-119. doi: 10.1016/j.amsu.2020.08.045. PMID: 32983429; PMCID: PMC7493078 


\section{Figures}

1 Fig 1: Frequency of educational activities before and after COVID

Prior to the pandemic what was the approximate frequency of educational activities in your program?
돌 Daily = Weekly
- Twice a Month
Monthly
a Biannual
annual

A Since the declaration of COVID-19 based restrictions on March 10th, what is the current freauencv of your education in comparison to the previous state?

a Daily = Weekly $=$ Twice a Month $=$ Monthly $=$ Biannual $=$ Not happening at all

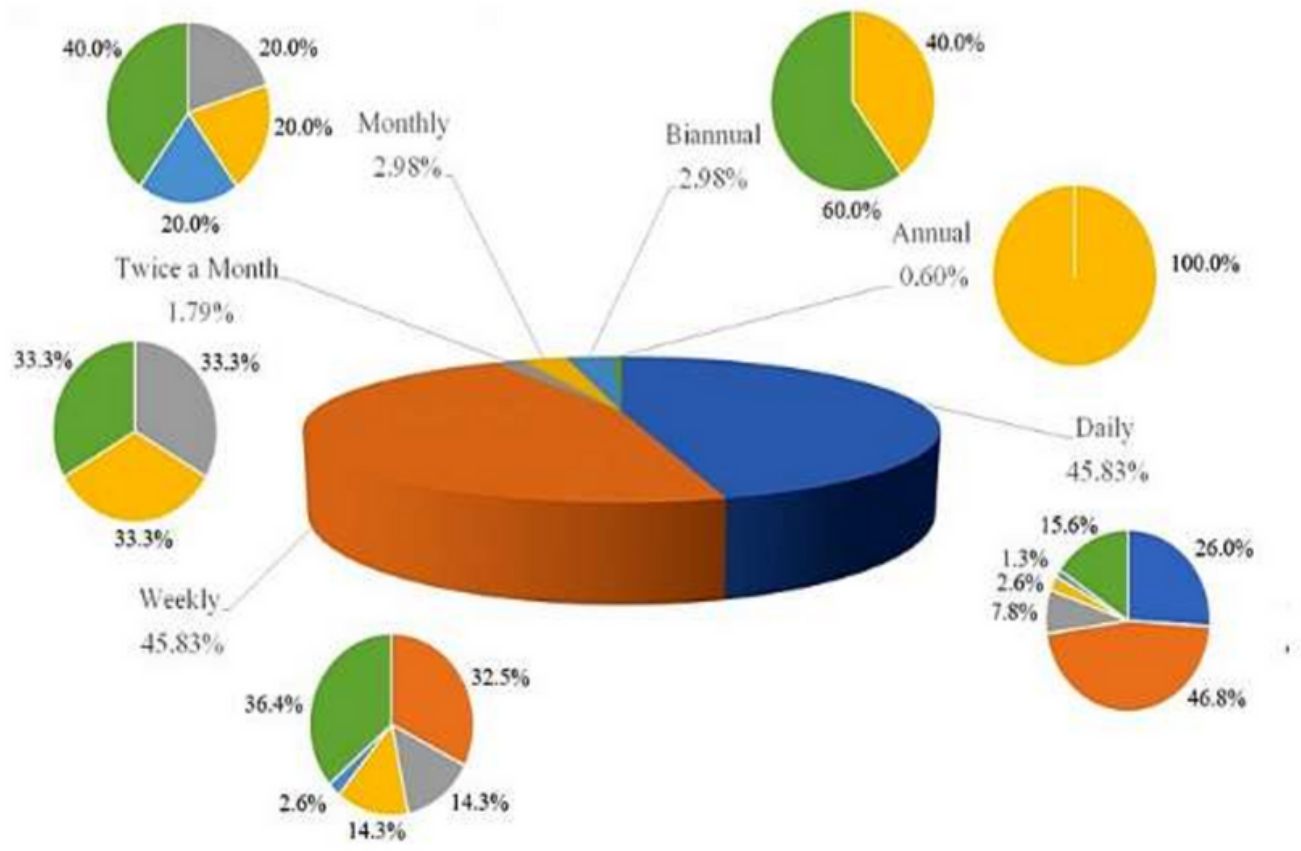

\section{Figure 1}

Frequency of educational activities before and after COVID 
Fig 2. Challenges faced by faculty during COVID 19

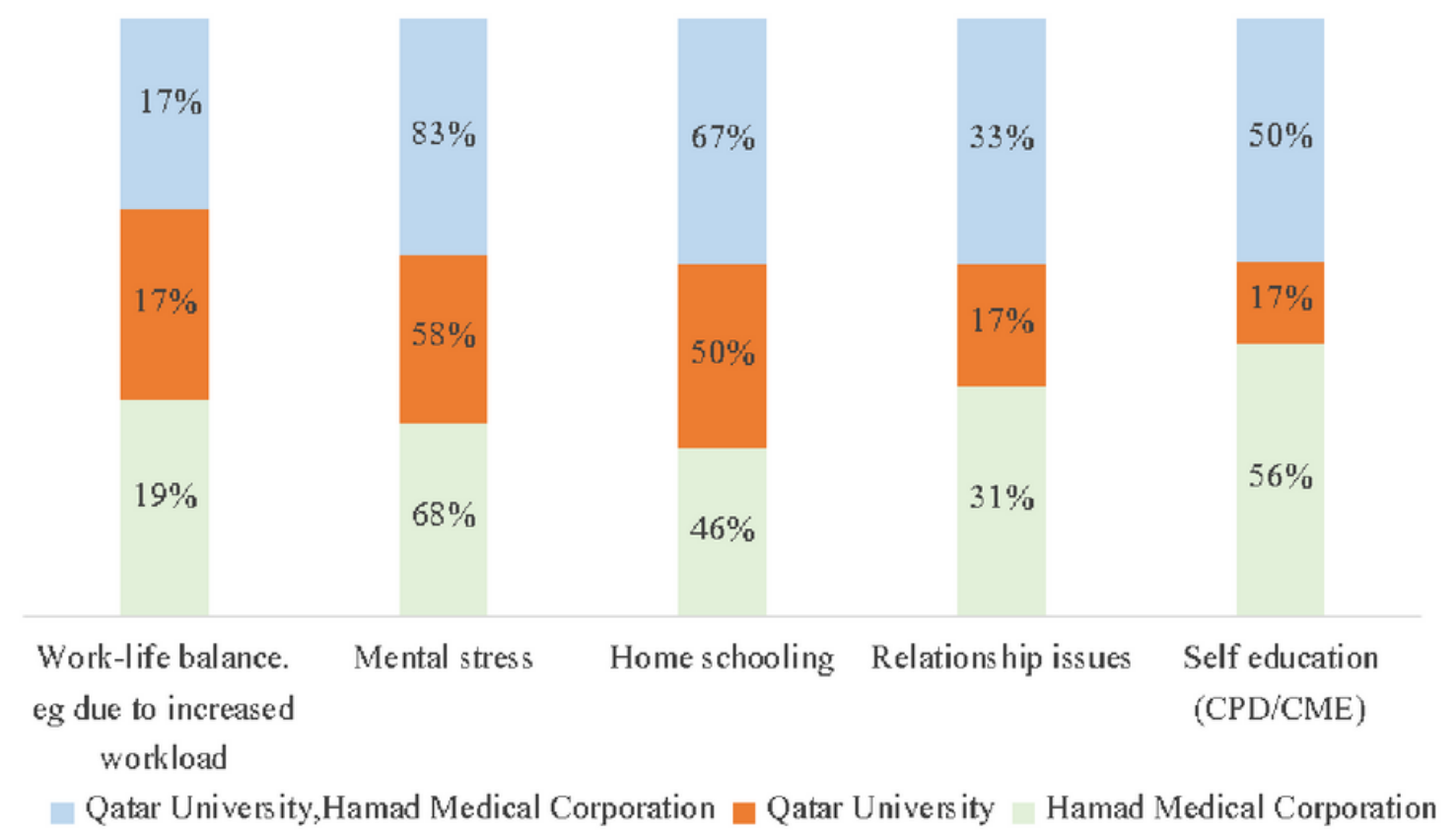

Figure 2

Frequency of educational activities before and after COVID 
Fig 3. Faculty's confidence in providing education via e-learning.

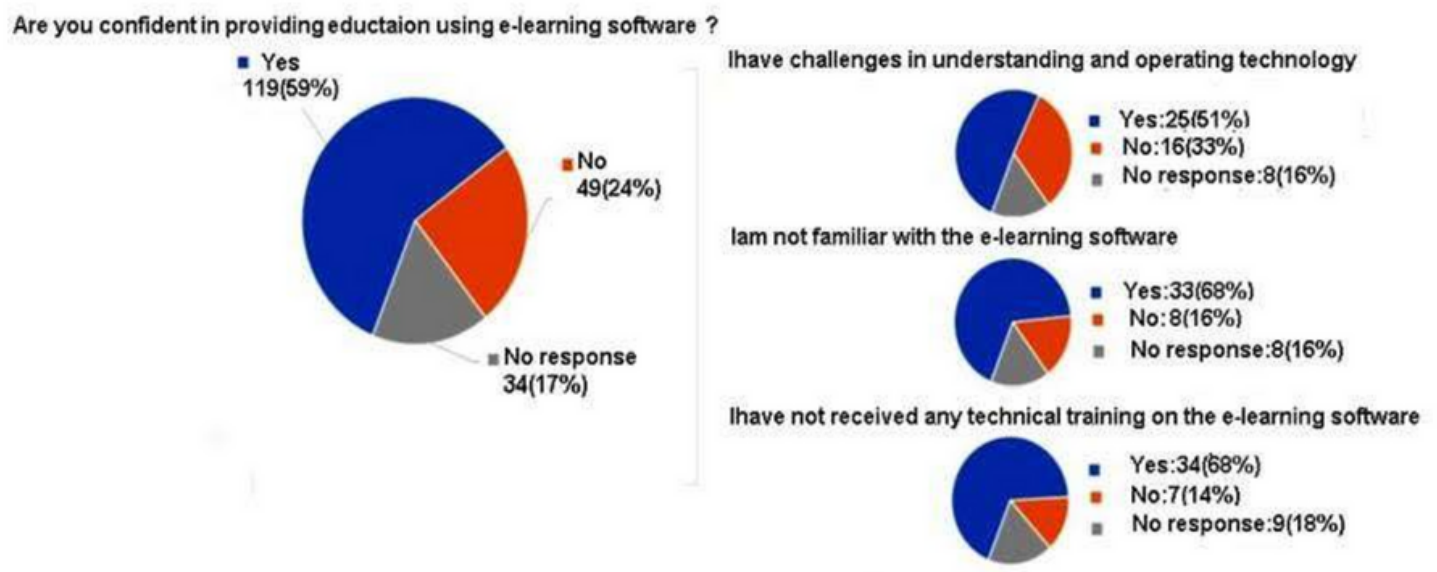

Figure 3

Faculty's confidence in providing education via e-learning.

\section{Supplementary Files}

This is a list of supplementary files associated with this preprint. Click to download.

- S1Appendix.docx

- S2Appendix1.docx

- S1Table.docx

- S2Table.docx

- S3Table.docx 